\title{
Roles of Toll-Like Receptors in Natural Interferon-Producing Cells as Sensors in Immune Surveillance
}

\author{
Tomoki Ito, Ryuichi Amakawa, and Shirou Fukuhara
}

\begin{abstract}
Natural IFN- $\alpha / \beta$ producing cells (IPCs) play a central role in innate immunity against microbial infections. In primary immune responses, toll-like receptors (TLRs), as major pattern-recognition receptors, are essential for IPCs as well as other antigen presenting cell (APC) subsets to recognize microbes. IPCs unequivocally express TLR 7 and TLR9, and can respond to the respective ligand to produce IFN- $\alpha / \beta$ and to rapidly differentiate into dendritic cells (DCs). Thereby, IPCs can not only activate innate immune system but also provoke $\mathrm{T}$ cell responses. Thus, IPCs link innate and adaptive immunity through TLR system. In addition, recent work has revealed the regulatory system of DC subsets in response
\end{abstract}

\section{INTRODUCTION}

Natural IFN- $\alpha / \beta$ producing cells (IPCs), so-called plasmacytoid cells, are a unique hematopoietic cell type that differentiate into mature dendritic cells (DCs) [1,2]. IPCs are suggested to be of lymphoid origin $[3,4]$ and, accordingly, IPC-derived DCs are different from myeloid-lineage DCs such as monocyte-derived DCs or blood CD $11 \mathrm{c}^{+}$myeloid DCs (mDCs) in terms of their phenotypical and functional properties [5-7]. Upon viral infection, IPCs are activated and produce not only proinflammatory cytokines but also large amounts of IFN$\alpha / \beta$, thereby activating innate immunity and provoking adaptive immunity [8]. Therefore, IPCs can link innate and adaptive immunity during the process of their differentiation.

\section{Expression of TLRs in IPCs}

Interferon producing cell activation is triggered by pathogen recognition. How do IPCs recognize microbial

From the First Department of Internal Medicine, Kansai Medical University, Moriguchi, Osaka, Japan.

Address reprint requests to: Dr. Tomoki Ito, MD, First Department of Internal Medicine, Kansai Medical University, 10-15 Fumizono-cho, Moriguchi City, Osaka 570-8506, Japan; Tel: +81 (6) 6993-9453; Fax: +81 (6) 6994-8344; E-mail: amakawa@takii.kmu.ac.jp.

Received July 22, 2002; accepted September 27, 2002. to microbial invasion. In this context, by the different but complementary expression profile of TLRs, IPCs together with myeloid APC subsets constitute a rational system of immune surveillance that can cover a wide variety of pathogens and enlarge immune adjuvant effects. Human Immunology 63, 1120-1125 (2002). (c) American Society for Histocompatibility and Immunogenetics, 2002. Published by Elsevier Science Inc.

KEYWORDS: IFN- $\alpha / \beta$ producing cells; dendritic cells; Toll-like receptors (TLRs); TLR7; proinflammatory cytokines

pathogens? Recent research on Toll-like receptors (TLRs) will provide the answer. TLRs, which are phylogenetically well conserved, are type I transmembrane proteins that are expressed on antigen presenting cells (APCs) including macrophages and DCs, and are major patternrecognition receptors for various pathogen-associated molecular patterns (PAMPs) in the innate immune system [9-13]. TLR signaling leads to activation of NF- $\mathrm{KB}$ through the adaptor protein MyD88-dependent pathway and induces a battery of immune adjuvant effects. The expression of TLR family members (TLR1-10) in human immune cells including IPCs and other DC subsets has been described by several groups (Table 1) [14-18]. IPCs unequivocally express both TLR7 and TLR9, and low TLR1, TLR6, and TLR10. On the other hand, blood immature $\mathrm{CD} 11 \mathrm{c}^{+} \mathrm{mDC}$ and monocytes are shown to have a similar TLR expression profile. Although the expression level is variable, both blood $\mathrm{mDCs}$ and monocytes express TLR1, TLR2, TLR4, TLR5, TLR6, and TLR8. Notably, blood mDCs selectively express TLR3. There is controversy surrounding in TLR7 expression in these blood myeloid APCs; the expression is undetectable or at low level. Thus, IPCs and myeloid APCs express a different TLR repertoire. 
TABLE 1 Functional TLR repertoire in human DC subsets

\begin{tabular}{|c|c|c|c|}
\hline & $\begin{array}{c}\text { IPCs } \\
\text { (plasmacytoid } \\
\text { DC precursors) }\end{array}$ & $\begin{array}{l}\text { Blood CD11c } \\
+ \text { DCs (immature } \\
\text { myeloid DCs) }\end{array}$ & $\begin{array}{l}\text { Monocytes } \\
\text { (myeloid DC } \\
\text { precursors) }\end{array}$ \\
\hline \multicolumn{4}{|l|}{ Expression of TLRs } \\
\hline TLR1 & low & + & + \\
\hline TLR2 & - & + & + \\
\hline TLR3 & - & + & - \\
\hline TLR4 & - & low & + \\
\hline TLR5 & - & low & + \\
\hline TLR6 & low & low & low \\
\hline TLR7 & + & low* & low $*$ \\
\hline TLR8 & - & low & + \\
\hline TLR9 & + & - & - \\
\hline TLR10 & low & low & - \\
\hline \multicolumn{4}{|l|}{ Cytokine production in response to ligand for TLRs } \\
\hline PGN (ligand for TLR2) & - & IL-12/IL-6/TNF- $\alpha$ & IL-6/TNF- $\alpha$ \\
\hline Poly I:C (ligand for TLR3) & - & IL-12/IFN- $\alpha$ & - \\
\hline LPS (ligand for TLR4) & - & IL-12/IL-6 & IL-6/TNF- $\alpha$ \\
\hline Flagellin (ligand for TLR5) & $?$ & $?$ & $?$ \\
\hline Imidazoquinoline compounds (ligands for TLR7) & IFN- $\alpha$ & IL-12 & $?$ \\
\hline CpG-ODNs (ligands for TLR9) & IFN- $\alpha$ & - & - \\
\hline
\end{tabular}

* Expression level in the subsets is in an argument among the report (Ref. 14-18); undetectable or in low level.

Abbreviations: DC = dendritic cells; IPC = interferon producing cells; LPS = lipopolysaccharide; PGN = peptidoglycan; TLR $=$ Toll-like receptor.

\section{Differential Responsiveness Through TLR} Signaling in IPCs and Myeloid DC Subsets

TLR2 and TLR 4 are essential for the recognition of peptidoglycan (PGN) from gram-positive bacteria and lipopolysaccharide (LPS) from gram-negative bacteria, respectively [19, 20]. Together with TLR2, TLR1 is associated with the recognition of bacterial or spirochetal lipoproteins $[21,22]$ and TLR6 co-recognizes mycoplasmal lipopeptide [12]. TLR5 and TLR9 recognize bacterial flagellin and bacterial DNA containing unmethylated CPG motifs, respectively [23-25]. TLR3 is involved in recognition and signal transduction induced by double-stranded (ds) RNA synthesized from viruses [26]. In accordance with the TLR expression, IPCs recognize CPG-oligonucleotides (ODNs), but not PGN or LPS, and thereby rapidly produce IFN- $\alpha / \beta$ and develop into mature DCs [14, 27-29]. By contrast, blood CD11c ${ }^{+}$ $\mathrm{mDCs}$ and monocytes respond to PGN or LPS, but not CpG-ODNs, to produce different sets of proinflammatory cytokines (i.e. TNF- $\alpha$, IL-6, or IL-12) $[14,16]$. In addition, polyinosinic-polycytidylic acid (poly I:C), a mimic of viral RNA, selectively stimulates blood mDCs to produce both IFN- $\alpha / \beta$ and IL-12 and to undergo their maturation [27]. Thus, depending on the differential expression of cognate TLRs, IPCs, blood CD $11 \mathrm{c}^{+} \mathrm{mDCs}$, or monocytes evoke distinct responsiveness in the production of different sets of proinflammatory cytokines in response to the respective TLR ligands from invading pathogens. Therefore, they may induce appropriate in- nate immune responses and also dictate the type of adaptive immune responses (Figure 1).

\section{TLR7, a New Member of TLRs, Involvement in IPC Functions}

Among the ten members of TLRs, the natural ligands for TLR7, TLR8, and TLR10 are unknown at present. However, a search for ligands of TLRs using gene-deficient mice has recently shown that synthetic compounds with antiviral activity are the ligands for TLR7 [30]. These are imidazoquinoline compounds, imiquimod and its derivative, resiquimod (R-848), and have potent antiviral and antitumor properties in animals [31-34]. In fact, imiquimod has been clinically approved for the treatment of genital warts caused by human papillomavirus [35]. It has been demonstrated in experiments using gene-deficient mice that these antiviral compounds activate immune cells, including macrophages, bone marrow-derived DCs, and splenocytes, via the TLR7-MyD88dependent signaling pathway. Human TLR7 can confer $\mathrm{R}-848$ responsiveness in experiments using transfected human embryonic kidney (HEK) 293 cells [30].

Several studies using a quantitative PCR method have shown that TLR7 is expressed in IPCs substantially, but in blood mDCs or in monocytes only at low levels [15-18]. However, not only IPCs but also blood mDCs can respond to imidazoquinoline compounds with enhanced survival and upregulation of costimulatory molecules such as CD40, CD80, and CD86 [18]. These 


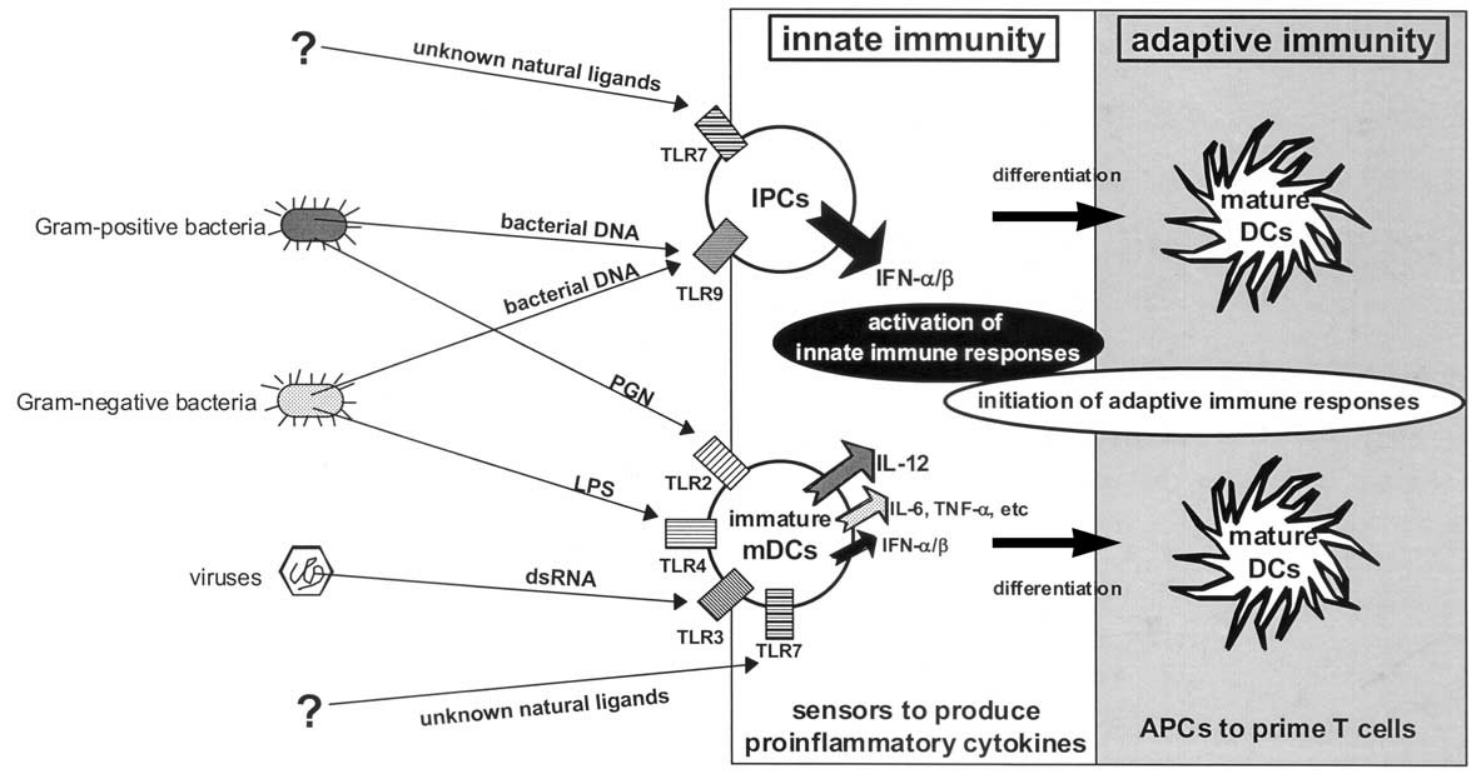

FIGURE 1 Functions of two blood dendritic cell (DC) subsets, interfernon producing cells (IPCs) and blood CD11c ${ }^{+}$ mDCs, by sensing microbial components through toll-like receptors (TLRs). IPCs and blood mDCs can respond to a wide variety of pathogens through different, but complementary, sets of TLRs in immune surveillance. These subsets produce the different sets of proinflammatory cytokines to the respective TLR ligands from invading pathogens, and may cooperate in immune responses against specific microbial pathogens. Thereby, they may induce appropriate innate immune responses and also dictate the type of adaptive immune responses.

effects of TLR7 ligands on IPCs are equivalent to those of CpG-ODNs through TLR9. Accordingly, TLR7 expression on IPCs and on blood mDCs might be enough to transmit the biological effects. Interestingly, TLR7 ligands exhibit differential cytokine inducing effects in different DC subsets: IFN- $\alpha$ in IPCs versus IL-12 in $m D C s[18]$. The TLR7 ligands, when injected into mice, can also elevate serum levels of IFN- $\alpha$ and IL-12 [30]. It is of note that TLR7 is phylogenetically closely related to TLR9. In addition to TLR9, TLR7 is a possible new member of the TLR family which has the potential to evoke IFN- $\alpha$ production from IPCs. Viral infection enhances TLR7 mRNA expression in human macrophages, but the presence of neutralizing anti-IFN- $\alpha / \beta$ Abs blocks this effect, while exogenous IFN- $\alpha$ directly upregulates TLR7 mRNA in macrophages [36]. Also in IPCs, TLR $7 \mathrm{mRNA}$ is upregulated in response to IFNinducing CpG-ODNs, but not to IL-3 [17]. These findings suggest that TLR7 expression on IPCs is positively modulated by IFN- $\alpha / \beta$, and that a positive feedback mechanism may control IFN- $\alpha$ production through
TLR7 signaling. Thus, the TLR7 system in IPCs may efficiently function in the event of microbial invasion.

Though there is debate regarding the ability of IPCs to produce IL-12 in response to some stimuli, it is known TLR7 is unable to induce a significant amount of IL-12 [18]. TLR7 ligands have also no capacity to induce IFN- $\alpha$ production from blood mDCs [18]. Thus, signaling through the same receptor results in the induction of subset-specific cytokine production. So far there has been a question whether cytokine production from a given DC subset is determined by cell lineage or by pathogenic stimuli that DCs receive. TLR9 and TLR2/TLR4 are expressed in either IPCs or myeloid APC subsets, and each subset differentially responds to the respective TLR ligands, as mentioned above. These findings favor the idea that cytokine production is determined by TLR expression on distinct DC subsets. However, the differential cytokine production from TLR7-stimulated IPCs and blood mDCs may indicate that DC lineage as well as TLR expression are decisive factors affecting DC response.

It remains unclear why TLR7 exerts differential outcomes in IPCs and blood mDCs. In response to LPS, DC-derived cytokine induction depends on MyD88, whereas DC maturation can proceed without MyD88, in the gene-deficient mice model [37]. These results indicate that MyD88 is a bifurcation point in TLR4 signaling. However, the effects of TLR7 signaling completely depend on MyD88 [30]. Therefore, it is likely that there is another bifurcation point leading to the synthesis of IFN- $\alpha$ or IL-12. Furthermore, it has been recently reported that the activation of NF- $\kappa \mathrm{B}$ is observed in 
HEK293 cells transiently transfected with human TLR8 in response to imidazoquinoline R-848 [38], as in the case of HEK293 cells transfected with human TLR7. Blood mDCs are shown to express not only TLR7 but also TLR8 at low levels, although the expression of TLR8 is not detected in IPCs at all. It remains unknown how TLR8 signaling is involved in blood $\mathrm{mDC}$ response to the imidazoquinoline compounds. Considering that TLR7 and TLR8 show high homology in their molecular structures [39], it is possible that TLR7 or TLR8 just work redundantly in blood mDCs. Identification of TLR7- or TLR8-specific ligands could provide clearer answers.

In B cells, TLR7 is also detected [17]. B cells show in vitro blast formation in response to TLR7 ligands [40], but in vivo roles of TLR7 signaling in B cells are so far unknown. Future identification of natural ligands for TLR7 will be important to clarify the pathophysiologic roles of this receptor in immunity. Until then, however, the imidazoquinoline compounds are useful tools to study the biological functions as well as the signaling pathway via TLR7.

\section{Rational Repertoire of TLRs in DC System in Innate Immunity}

Because IFN- $\alpha / \beta$ is essential in antiviral and antibacterial innate immunity [41], IPCs may play a central role in the immune responses against infections by sensing microbial invasion. The limited TLR expression on IPCs suggests that IPCs are incapable of responding to all microbial components. However, the different, but complementary, expression profiles of TLRs among IPCs and other myeloid APC subsets may cover a wide variety of pathogens. It is very likely that a given pathogen can activate not only IPCs but also myeloid APC subsets simultaneously through multiple TLR pathways (Figure 1). For example, upon invasion of Gram-negative bacteria, the bacteria-derived LPS and CpG DNA can simultaneously activate myeloid APCs and IPCs, respectively, and may contribute to the establishment of antibacterial immune responses. Similarly, in antiviral immunity, intracellular viral infection directly stimulates IPCs and virus-synthesized dsRNA also can activate immature mDCs via TLR3. Thus, the TLR network between IPCs and other myeloid APCs constitutes a kind of rational fail-safe system and thereby, these subsets may cooperate to enlarge innate immune responses against diverse microbial pathogens.

IPC-Derived DCs in Adaptive Immunity, Possible Involvement in TLRs

It is unclear how TLR-mediated microbial recognition by DC results in antigen processing and presentation. However, the downregulation of TLR expression during
DC differentiation [16] implicates a functional shift; DC precursors act as particular cytokine producers in innate immunity through microbial recognition, and mature DCs act as APCs in priming T cells in adaptive immunity. Furthermore, after pathogen recognition through TLRs, either IPCs or blood mDCs differentiate into mature DCs that can prime naive $T$ cells [27]. Recent progress has clarified a functional plasticity of DCs in adaptive immunity [5-7, 42]. In this context, DCs mainly regulate the quality of Th cell responses by DC-derived cytokines, in particular IL-12 or IFN- $\alpha / \beta$. Most myeloid DCs have some capacity to produce IL-12 and, thereby, to induce Th1 development. However, this capacity varies with the conditions of their maturational stage or stimulation delivered to DCs [43-48]. A similar functional plasticity is observed in IPC-derived DCs $[8$, 49-51]. When IPCs sense viruses, they differentiate into mature DCs that can direct naive Th cells toward Th1like (IFN- $\gamma$ and IL-10 producing) cells through the IPC-derived IFN- $\alpha / \beta$. When IPCs develop into DCs upon exposure to IL-3, which is mainly produced under allergic conditions, these DCs induce Th2 cells and have no capacity to produce IFN- $\alpha / \beta$ and/or IL- 12 . In response to pathogenic stimuli through TLRs, myeloid DC subsets can skew naive Th cells into Th1 cells. In fact, every susceptible TLR ligand can induce IL-12 production from immature mDCs and monocytes [16]. Also, when IPCs respond to ligands for TLR7 [18] or TLR9 [29], IPC-derived DCs can induce IFN- $\gamma$ producing Th cells through IFN- $\alpha / \beta$ suggesting that IPCs acquire Th1 (or Th1-like) inducing activity upon microbial invasion. In addition, the production of IL-12 by myeloid DCs triggered by some microbial stimuli $[52,53]$ and the production of IFN- $\alpha$ by IPCs stimulated by CpG-ODN [15] is amplified by CD40 ligation. These findings suggest that their Th1-inducing activities through the TLR system can be well performed in the T-cell priming process. Taken together, to eliminate invading pathogens, both types of DCs are programmed to make different innate responses in terms of cytokine production and can eventually support anti-microbial Th1 responses in a subset-specific cytokine dependent manner (Figure $1)$.

In this article, we have focused on the role of TLRs in the functions of the DC system, including IPCs. However other cell surface receptors of DC such as mannose receptors, CD1 family, or DC-SIGN may be important for pathogen recognition. The interesting points are how signalings from TLRs and those from the phagocytic receptors are connected at the molecular level, and how these signals contribute to the functions of DCs as APCs. These points should be clarified, to provide a better understanding of DC-mediated immunity. 
ACKNOWLEDGMENTS

We thank Dr. M. Inaba and Dr. T. Kaisho for critical reading of the manuscript.

\section{REFERENCES}

1. Grouard G, Rissoan MC, Filgueira L, Durand I, Banchereau J, Liu YJ: The enigmatic plasmacytoid T cells develop into dendritic cells with Interleukin (IL)-3 and CD40-ligand. J Exp Med 185:1101, 1997.

2. Siegal FP, Kadowaki N, Shodell M, Fitzgerald-Bocarsky PA, Shah K, Ho S, Antonenko S, Liu YJ: The nature of the principal type I interferon-producing cells in human blood. Science 284:1835, 1999.

3. Spits H, Couwenberg F, Bakker AQ, Weijer K, Uittenbogaart $\mathrm{CH}$ : Id 2 and Id 3 inhibit development of $\mathrm{CD} 34^{+}$ stem cells into predendritic cell (pre-DC) 2 but not into pre-DC1. Evidence for a lymphoid origin of pre-DC2. J Exp Med 192:1775, 2000.

4. Res PC, Couwenberg F, Vyth-Dreese FA, Spits H: Expression of $\mathrm{pT} \alpha \mathrm{mRNA}$ in a committed dendritic cell precursor in the human thymus. Blood 94:2647, 1999.

5. Liu YJ: Dendritic cell subsets and lineages, and their functions in innate and adaptive immunity. Cell 106:259, 2001.

6. Shortman K, Liu YJ: Mouse and human dendritic cell subtypes. Nat Rev Immunol 2:151, 2002.

7. Liu YJ, Kanzler H, Soumelis V, Gilliet M: Dendritic cell lineage, plasticity and cross-regulation. Nat Immunol 2:585, 2001.

8. Kadowaki N, Antonenko S, Lau JYN, Liu YJ: Natural interferon $\alpha / \beta$-producing cells link innate and adaptive immunity. J Exp Med 192:219, 2000.

9. Medzhihtov R, Janeway C Jr: Innate immunity: the virtues of a nonclonal system of recognition. Cell 91:295, 1997.

10. Medzhihtov R, Janeway C Jr: Innate immune recognition: mechanism and pathways. Immunol Rev 173:89, 2000.

11. Aderem A, Ulevitch RJ: Toll-like receptors in the induction of the innate immune response. Nature 406:782, 2000.

12. Akira S, Takada K, Kaisho T: Toll-like receptors: critical proteins linking innate and acquired immunity. Nat Immunol 2:675, 2001.

13. Kaisho T, Akira S: Dendritic-cell function in toll-like receptor- and MyD88-knockout mice. Trends Immunol 22:78, 2001.

14. Jarrossay D, Napolitani G, Colonna M, Sallusto F, Lanzavecchia A: Specialization and complementarity in microbial molecule recognition by human myeloid and plasmacytoid dendritic cells. Eur J Immunol 31:3388, 2001.

15. Krug A, Towarowski A, Britsch S, Rothenfusser S, Hornung V, Bals R, Giese T, Engelmann H, Endres S, Krieg AM, Hartmann G: Toll-like receptor expression reveals
CpG DNA as a unique microbial stimulus for plasmacytoid dendritic cells which synergizes with CD40 ligand to induce high amounts of IL-12. Eur J Immunol 31:3026, 2001.

16. Kadowaki N, Ho S, Antonenko S, Malefyt RW, Kastelein RA, Bazan F, Liu YJ: Subsets of human dendritic cell precursors express different toll-like receptors and respond to different microbial antigens. J Exp Med 194:863, 2001.

17. Hornung V, Rothenfusser S, Britsch S, Krug A, Jahrsdörfer B, Giese T, Endres S, Hartman G: Quantitative expression of Toll-like receptor 1-10 mRNA in cellular subsets of human peripheral blood mononuclear cells and sensitivity to $\mathrm{CpG}$ oligodeoxynucleotides. J Immunol 168:4531, 2002.

18. Ito T, Amakawa R, Kaisho T, Hemmi H, Tajima K, Uehira K, Ozaki Y, Tomizawa H, Akira S, Fukuhara S: Interferon-a and interleukin-12 are induced differentially by Toll-like receptor 7 ligands in human blood dendritic cell subsets. J Exp Med 195:1507, 2002.

19. Takeuchi O, Hoshino T, Kawai T, Sanjo H, Takada H, Ogawa T, Takeda K, Akira S: Differential roles of TLR2 and TLR4 in recognition of gram-negative and grampositive bacterial cell wall components. Immunity 11 443, 1999.

20. Schwandner R, Dziarski R, Wesche H, Rothe M, Kirschning CJ: Peptidoglycan- and lipoteichoic acid-induced cell activation is mediated by toll-like receptor 2 . J Biol Chem 274:17406, 1999.

21. Takeuchi O, Sato S, Horiuchi T, Hoshino K, Takeda K, Dong Z, Modlin RL, Akira S: Role of toll-like receptor 1 in mediating immune response to microbial lipoproteins. J Immunol 169:10, 2002.

22. Alexopoulou L, Thomas V, Schnare M, Lobet Y, Anguita J, Schoen RT, Medzhitov R, Fikrig E, Flavell RA. Hyporesponsiveness to vaccination with Borrelia burgdorferi OspA in humans and in TLR1- and TLR2-deficient mice. Nat Med 8:878, 2002.

23. Hayashi F, Smith KD, Ozinsky A, Hawn TR, Yi EC, Goodlett DR, Eng JK, Akira S, Underhill DM, Aderem A: The innate immune response to bacterial flagellin is mediated by Toll-like receptor 5. Nature 410:1099, 2001.

24. Hemmi H, Takeuchi O, Kawai T, Kaisho T, Sato S, Sanjo $\mathrm{H}$, Matsumoto $\mathrm{M}$, Hoshino $\mathrm{K}$, Wagner $\mathrm{H}$, Takeda $\mathrm{K}$, Akira S: A Toll-like receptor recognizes bacterial DNA. Nature 408:740, 2000.

25. Bauer M, Redecke V, Ellwart JW, Scherer B, Kremer JP, Wagner H, Lipford GB: Human TLR9 confers responsiveness to bacterial DNA via species-specific CpG motif recognition. Proc Natl Acad Sci USA 98:9237, 2001.

26. Alexopoulou L, Holt AC, Medzhitov R, Flavell RA: Recognition of double-stranded RNA and activation of NF-кB by toll-like receptor 3. Nature 413:732, 2001.

27. Kadowaki N, Antonenko S, Liu YJ: Distinct CpG DNA 
and polyinosinic-polycytidylic acid double-stranded RNA, respectively, stimulate $\mathrm{CD}_{11 c^{-}}$type 2 dendritic cell precursors and $\mathrm{CD}_{11 \mathrm{c}^{+}}$dendritic cells to produce type I IFN. J Immunol 166:2291, 2001.

28. Krug A, Rothenfusser S, Hornung V, Jahrsdörfer B, Blackwell S, Ballas ZK, Endres S, Krieg AM, Hartmann $\mathrm{G}$ : Identification of $\mathrm{CpG}$ oligonucleotide sequences with high induction of IFN- $\alpha / \beta$ in plasmacytoid dendritic cells. Eur J Immunol 31:2154, 2001.

29. Bauer M, Redecke V, Ellwart JW, Scherer B, Kremer JP, Wagner H, Lipford GB: Bacterial CpG-DNA triggers activation and maturation of human CD11c-, CD123 dendritic cells. J Immunol 166:5000, 2001.

30. Hemmi H, Kaisho T, Takeuchi O, Sato S, Sanjo H, Hoshino K, Horiuchi T, Tomizawa H, Takeda K, Akira S: Small anti-viral compounds activate immune cells via TLR7-MyD88-dependent signaling pathway. Nat Immunol 3:196, 2002.

31. Miller RL, Gerster JF, Owens ML, Slade HB, Tomai MA: Imiquimod applied topically: a novel immune response modifier and new class of drug. Int J Immunopharmacol 21:1, 1999.

32. Harrison CJ, Miller RL, Bernstein DI: Posttherapy suppression of genital herpes simplex virus (HSV) recurrences and enhancement of HSV-specific T-cell memory by imiquimod in guinea pigs. Antimicrob Agents Chemother 38:2059, 1994.

33. Chen M, Griffith BP, Lucia HL, Hsiung GD: Efficacy of S26308 against guinea pig cytomegalovirus infection. Antimicrob Agents Chemother 32:678, 1988.

34. Bernstein DI, Harrison CJ, Tomai MA, Miller RL: Daily or weekly therapy with resiquimod (R-848) reduces genital recurrences in herpes simplex virus-infected guinea pigs during and after treatment. J Infect Dis 183:844, 2001.

35. von Krogh G, Lacey CJ, Gross G, Barrasso R, Schneider A: European course on HPV associated pathology: guideline for primary case physicians for the diagnosis and management of anogenital warts. Sex Transmem Infect 76:162, 2000.

36. Miettinen M, Sareneva T, Julkunen I, Matikainen S: IFNs activate toll-like receptor gene expression in viral infections. Genes Immunol 2:349, 2001.

37. Kaisho T, Takeuchi O, Kawai T, Hoshino K, Akira S: Endotoxin-induced maturation of MyD88-deficient dendritic cells. J Immunol 166:5688, 2001.

38. Jurk M, Heil F, Vollmer J, Schetter C, Krieg M, Wagner H, Lipford G, Bauer S: Human TLR7 or TLR8 independently confer responsiveness to the antiviral compound R-848. Nat Immunol 3:499, 2002.

39. Du X, Poltorak A, Wei Y, Beutler B: Three novel mammalian toll-like receptors: gene structure, expression, and evolution. Eur Cytokine Network 11:362, 2000.

40. Tomai MA, Imbertson LM, Stanczak TL, Tygrett LT, Waldschmidt TJ: The immune response modifiers imi- quimod and R-848 are potent activators of B lymphocytes. Cell Immunol 203:55, 2000.

41. Bogdan C: The function of type I interferons in antimicrobial immunity. Curr Opin Immunol 12:419, 2000.

42. Lanzavecchia A, Sallusto F: Regulation of T cell immunity by dendritic cells. Cell 106:263, 2001.

43. Ito T, Amakawa R, Inaba M, Ikehara S, Inaba K, Fukuhara S: Differential regulation of human blood dendritic cell subsets by IFNs. J Immunol 166:2961, 2001.

44. Vieira PL, de Jong EC, Wierenga EA, Kapsenberg ML, Kalinski P: Development of Th1-inducing capacity in myeloid dendritic cells requires environmental instruction. J Immunol 164:4507, 2000.

45. de Jong EC, Vieira PL, Kalinski P, Schuitemaker JHN, Tanaka Y, Wierenga EA, Yazdanbakhsh M, Kapsenberg ML: Microbial compounds selectively induce Th1 cellpromoting or Th2 cell-promoting dendritic cells in vitro with diverse Th cell-polarizing signals. J Immunol 168: 1704, 2002.

46. Langenkamp A, Messi M, Lanzavecchia A, Sallusto F: Kinetics of dendritic cell activation: impact on priming of Th1, Th2 and nonpolarized T cells. Nat Immunol 1:311, 2000.

47. Jonuleit H, Schmitt E, Schuler G, Knop J, Enk AH: Induction of interleukin 10-producing, nonproliferating $\mathrm{CD}^{+} \mathrm{T}$ cells with regulatory properties by respective stimulation with allogeneic immature human dendritic cells. J Exp Med 192:1213, 2000.

48. Soumelis V, Reche PA, Kanzler H, Yuan W, Edward G, Homey B, Gilliet M, Ho S, Antonenko S, Lauerma A, Smith K, Gorman D, Zurawski S, Abrams J, Menon S, McClanahan T, de Waal-Malefyt R, Bazan F, Kastelein RA, Liu YJ: Human epithelial cells trigger dendritic cell-mediated allergic inflammation by producing TSLP. Nat Immunol 3:1, 2002.

49. Rissoan MC, Soumelis V, Kadowaki N, Grouard G, Briere F, Malefyt RW, Liu YJ: Reciprocal control of T helper cell and dendritic cell differentiation. Science 283:1183, 1999.

50. Cella M, Facchetti F, Lanzavecchia A, Colonna M: Plasmacytoid dendritic cells activated by influenza virus and CD40L drive a potent TH1 polarization. Nature Immunol 1:305, 2000.

51. Gilliet M, Liu YJ: Generation of human CD8 T regulatory cells by CD40 ligand-activated plasmacytoid dendritic cells. J Exp Med 195:695, 2002.

52. Hilken CMU, Kalinski P, de Boer M, Kapsenberg ML: Human dendritic cells require exogenous interleukin-12inducing factors to direct the development of naive T-helper cells toward the Th1 phenotype. Blood 90:1920, 1997.

53. Schulz O, Edwards AD, Schito M, Aliberti J, Manickasingham S, Sher A, Reis e Sousa C: CD40 triggering of heterodimeric IL-12 p70 production by dendritic cells in vivo requires a microbial priming signal. Immunity 13 : 453, 2000. 